\title{
Grupo de Ensino de Geologia: Inovação Curricular no Instituto de Geociências USP (1973-1978)
}

\author{
Celso Dal Ré Carneiro ${ }^{1}$, Ivan Amorosino do Amaral ${ }^{2}$, Pedro Wagner Gonçalves ${ }^{3}$, Maria Cristina Motta de Toledo 4 \\ 1 Instituto de Geociências, Universidade Estadual de Campinas, Campinas, SP. - cedrec@ige.unicamp.br \\ 2 Faculdade de Educação, Universidade Estadual de Campinas, Campinas, SP. - ivan_amorosinodoamaral@yahoo.com.br \\ 3 Instituto de Geociências, Universidade Estadual de Campinas, Campinas, SP. - pedrog@ige.unicamp.br \\ 4 EACH / Ciências da Natureza, Universidade de São Paulo USP. - mcristoledo@gmail.com
}

Citation: Carneiro C.D.R., Ivan Amorosino do Amaral I.A., Gonçalves P.W., Toledo M.C.M.. 2016. Grupo de Ensino de Geologia: Inovação Curricular no Instituto de Geociências USP (1973-1978). Terræ Didatica, 13(1):64-65. < http://www.ige.unicamp.br/terraedidatica/>.

\section{Resumo}

O Grupo de Ensino de Geologia surgiu no início de 1973, quando o Instituto de Geociências (IG) da Universidade de São Paulo (USP) passou a oferecer disciplina básica de Geologia Geral para alunos de Geologia, Geografia e Ciências Biológicas e optativa para cursos como Física, Química e Matemática (sigla GGG-121). A carga horária de 60 horas e os cerca de 500 alunos atendidos por ano exigiram alterações radicais: corpo docente, objetivos educacionais, conteúdo programático, metodologia de ensino e critérios de constituição de dez turmas cada ano, cinco por semestre. A equipe da disciplina teve autonomia para realizar mudanças (Amaral 2014), sendo coordenada por docente especializado no ensino de Geologia Introdutória no nível superior (IAA).

Introduziram-se ideias educacionais heterodoxas e inovadoras para os padrões da época na USP. Ali desaguaram resultados obtidos em iniciativas até então restritas às licenciaturas curtas, que apresentavam grande abertura para a inovação. A experiência repercutiu além das fronteiras da USP, superou o âmbito da Geologia Introdutória e contribuiu para mudanças no ensino da Geologia no País.

A década de 1960 se caracterizou pela tomada de consciência do advento da crise ambiental e foi pródiga em ideias pedagógicas inovadoras, com implicações em ensino-aprendizagem. Aumentava o interesse pelas Geociências como componente curricular independente no ensino básico, com a criação de disciplina optativa de Geociências no currículo do ensino médio oficial e abertura de Licenciatura em Geologia na Faculdade de Educação da USP. No âmbito das Ciências Geológicas, várias publicações exerceram grande influência no movimento inovador do ensino; algumas destacaram o caráter histórico da Geologia como parte de sua identidade como Ciência (Amaral 2014). Geologia Introdutória passou a ser designação genérica de quaisquer disciplinas que apresentassem conteúdo geológico a estudantes do nível superior, independente do enfoque programático. Um alicerce da visão interdisciplinar advinha da incorporação da Geologia como ciência histórica da natureza, sendo as Geociências a visão integrada da dinâmica atual da natureza.

Em 1978, o grupo desligou-se da universidade mas manteve o objetivo inicial, reaglutinando-se na Área de Educação Aplicada às Geociências (AEAG) no IG-Unicamp (Carneiro 2014). Pode-se afirmar que propostas como as defendidas pelo Grupo de Ensino de Geologia contribuíram para construção da base legal do Currículo Mínimo dos cursos de graduação de Geologia e Engenharia Geológica (SBGeo 1982); mais tarde, levaram à fundação do atuante Fórum Nacional de Cursos de Geologia e à definição das diretrizes curriculares nacionais desses cursos (Brasil 2012). Desdobramentos da experiência iniciada no IG-USP são o vasto acervo de dados reunidos na síntese $A$ formação do geólogo nas universidades brasileiras: um retrato de duas décadas 
(SBGeo 1984) e, anos mais tarde, a criação do curso de graduação em Geociências e Educação Ambiental (LIGEA) no IGc-USP. Em outra vertente, nos anos 1980, o enfoque de Geociências foi o grande inspirador da Proposta Curricular de Ciências para o $1^{\circ} \mathrm{Grau}$, oficializada em 1988 e vigente até 2008 .

A consolidação permanente do grupo de geólogos que haviam escolhido pesquisar e se tornar docentes dedicados à questão da educação em geologia, ocorreu com a institucionalização do IG-Unicamp e a concomitante transformação em 1996 da AEAG no Departamento de Geociências Aplicadas ao Ensino (DGAE), a criação pioneira do mestrado e doutorado em ensino de Geologia e sua posterior transformação no Programa de Pós-Graduação em Ensino e História de Ciências da Terra (PEHCT). Algumas conclusões extraídas de Amaral (2014), a seguir resumidas, emergem da experiência iniciada na USP:

Momentos de crise favorecem iniciativas de mudança, desde que se construam respostas convincentes ao desafio e os atores saibam como enfrentar as tradições culturais e a resistência de setores conservadores. A trajetória revela que a inovação educacional é processo complexo que se beneficia do trabalho coletivo e envolvimento autêntico das comunidades interessadas, sendo favorecida se houver colaboração de associações de classe. Não bastam boas ideias e boas intenções para sobrevivência de experiências de sucesso, sendo necessárias persistência e força política.

Modelos curriculares úteis em outros contextos podem aportar ideias e soluções inovadoras, mas devem sofrer o filtro de cada circunstância espacial e temporal, ganhando contornos que reflitam as necessidades e exigências do momento histórico e do desafio concreto em que se inserem.

A Geologia como ciência histórica da natureza introduz decisivamente no ensino fundamental das ciências da natureza a perspectiva interdisciplinar do ambiente terrestre e o enfoque sistêmico. São caracteres que a tornam singular e valiosa para formar as futuras gerações que deverão enfrentar a crise ambiental.

O sistema educativo formador do professor de Ciências acostumou-se a fragmentar e compartimentalizar os conhecimentos físicos, químicos, biológicos e geológicos. A Geologia moderna propõe o inverso, mas a comunidade geológica ainda não assumiu esse notável papel social e grande oportunidade profissional.

\section{Referências}

Amaral I.A.do. 2014. Raízes da mudança curricular ocorrida em 1973 na USP. Terra Didatica, 10(3):161-170. . (Anais Interfaces Geociências e Ensino: 40 anos de experiências (1973-2013), 23 e 24 de agosto de 2013, Campinas, SP. URL: http:// www.ige.unicamp.br/terraedidatica/V10_3/1114.html.

Amaral I.A.do, Macedo A.B., Carneiro C.D.R. 1976. Uma busca de renovação no ensino de Geociências. Bol. Paul. Geogr., (52):55-68.

Brasil. Ministério da Educação. Conselho Nacional de Educação. Câmara de Educação Superior. 2012. Resolução CNE/CES n. 387/2012, de 7 novembro de 2012. Institui as diretrizes curriculares nacionais para o curso de graduação em Geologia e em Engenharia Geológica, bacharelados. Brasília (DF), 7 nov. 2012. (Relator Luiz Roberto Liza Curi, Proc. No: 23001.000110/2007-41).

Carneiro C.D.R. 2014. O Fórum Nacional de Cursos de Geologia e as Diretrizes Curriculares Nacionais: histórico e perspectivas. Terrce Didatica, 10(3):191-203. (Anais Interfaces Geociências e Ensino: 40 anos de experiências (1973-2013), 23 e 24 de agosto de 2013, Campinas, SP. URL: http://www. ige.unicamp.br/terraedidatica/V10_3/4-110.html.

Sociedade Brasileira de Geologia (SBG) . 1984. A formação do geólogo nas universidades brasileiras: um retrato de duas décadas. São Paulo: SBG. 